\title{
Absolute Measure and the C.G.S. Units.
}

\section{By Sir George Greenhill.}

"W HAT is the matter with physics training for the engineer?" is a question asked to-day. The engineer will answer, "It is the C.G.S. source of arrogance and tyranny," following him even into the engineering laboratory, and his calculations in hydrostatics. He has no use for such minute units, as he works always to terrestrial gravitation measure of his world of existence, and C.G.S. is thrown aside as soon as the young engineer, gunner and navigator is liberated from the tyranny of the lecture and examination room, and he is free to talk and calculate in all the old units familiar to generations.

These C.G.S. units are described in Halsey's "Handbook for Draftsmen " as a "Monument of scientific zeal (misplaced)combined with ignorance of practical requirements." "The object of Weights and Measures is to weigh and measure, not merely to make calculations."

No wonder Prof. Hudson Beare maintained at the British Association at Hull the desirability of keeping the mathematics of the engineer distinct from the examination needs of the Science and Art, or even medical student in his research of a diploma, and that the teacher of engineers should preferably be an engineer himself. If he has to teach physics, it should be industrial physics, in their application on a large scale to constructional needs.

Mach pleaded age and infirmity for taking no hand in the translation of his work, and gave the translator a free hand. The opportunity was seized of making him sponsor of the C.G.S. system, and no other, by the ardent disciples of the Open Court. We find the same fervent advocacy of C.G.S. in our scientific schools over here, compelling even the engineering students to use their microscopic units to the exclusion of all others employed in his practical life.

A rival system, M.M.S. (millimetre-milligram second), still moreminute, was proposed in Germany, and is mentioned by Mach, but this was ironical. In France, Olivier, whose work was reviewed lately in NATURE, is pushing the M.T.S. system (metre-tonne-second) as better adapted for large scale work.

The M.K.S. (metre-kilogramme-second) system would suit most practical requirements, but this is rejected by the purist in units because it makes the density of water $1000, \mathrm{~kg} / \mathrm{m}^{3}$, instead of unity. But the advantage here is in keeping the air buoyancy in sight, as a correction of about $x \cdot 25$ on the last figure of the absolute density, in vacuo, as it ought to be tabulated. Suppose it was required to weigh $\mathrm{x}$ lb. or I ton of hydrogen in the scales for an airship; describe your procedure.

Absolute measure was first introduced into dynamical teaching under Prof. Tait in Edinburgh, although Tait never carried his Glasgow colleague with him to a full extent. Gauss had initiated the idea previously as essential in magnetic measurement all over the world.

Tait told us the idea struck him in his struggle with the Definitions in Chapter II of his "Dynamics of a Particle"; and then it burst on him as a revelation of the way out of a theoretical difficulty always a puzzle to him.
The idea fructified, and to-day we find absolute measure universal in all theoretical physics, and the engineer is blamed for sticking to his old gravitation units for mechanics. The electrician, however, is compelled to work absolute in his cosmical electromagnetism, broadcasting his theoretical results, depending only indirectly on the gravitation of the earth.

In Tait's procedure a change was made in the unit of what was then called mass, changing it from a vague sui generis into the Imperial Standard Pound, and then $\mathrm{P}=\mathrm{M} f$ implied a new unit of force, for which the name poundal was afterwards discovered, such that the heft of I lb. weight was $g$ of these units, poundals. The poundal was thus $I / g$ of the heft-weight of $I \mathrm{lb}$, say I/32, or half an ounce in round numbers. This unit was much too small for the engineer; he has refused to have anything to do with absolute measure, and jeers at the pedantry of calling the poundal a unit of weight, pointing to the precise language of the successive Acts of Parliament, from Nebuchadnezzar and earlier, down to our day.

\section{Weights and Measures Act, I878.}

\section{Imperial Measures of Weight and Capacity.}

I3. The weight in vacuo of the platinum weight mentioned in the first schedule of this Act and by this Act declared the imperial standard pound shall be the legal standard measure of weight and of measure having reference to weight and shall be called the imperial standard pound and shall be the only unit or standard measure of weight from which all weights and all measures having reference to weight shall be ascertained. [N.B.-No word mass occurs.]

Any person who sells by any denomination of weight or measure other than one of the imperial weights or measures or some multiple or part thereof, shall be liable to a fine not exceeding forty shillings for every such offence. Printer and publisher are liable for any act in contravention of this section.

So any one giving weight in poundals, in print or writing, would be liable to this fine. No mention is made in this Act of barometer or thermometer reading, required in the definition of the gallon, cubic measure ; weight in vacuo covers all such ambiguity of its measure, inserted for the first time in the draft of this Act; the omission was a source of great trouble when the need arose for a new Standard Pound.

Not a word in the Act about the attraction of the earth on the pound weight. Nothing is said about the pressure on the bottom of the box containing the pound weight, and the influence of local $g$, however it may vary down a mine, or up in the air, or away into space from one end of the world to the other.

The pound weight does not alter, brought out of its vacuum into the atmosphere, or even if it was carried away into space to the other end of the universe; it always remains the lump of platinum defined in the Act. At least this was the current belief until quite recently, before a distinction was made between Ruhmasse and Masse in Bewegung. 
If, however, the weight of a pound is to mean something quite distinct from the pound weight, as the force with which it is attracted by the earth, the confusion of language and measurement is intolerable.

It is not correct to say the word weight is always to be reserved, strictly speaking, for the subsidiary meaning of earth attraction, as the word was in use long before such distinction was made or understood, and is to be found in ordinary language and writing, e.g. in Shakespeare, the Bible, and other of our classics, in both senses, but usually in the meaning of the Act of Parliament.

The latest discoveries of atomic theory have forced a reconsideration of former definitions of fundamental units, considered unassailable on the Newtonian doctrine. Language again has failed to recognise these new distinctions. C.G.S. units are displaced in the relativity theory, where the unit of time is nearly Iooo years, instead of our terrestrial second, adopted to keep $g$ down to a reasonable figure, $98 \mathrm{I}$, or 32 .

"Space-Time-Matter" of Hermann Weyl will give some idea of the latest lofty ideas of the universe, beyond the scope of these humble elementary remarks in defence of the old Newtonian mechanics-all the engineer has, so far, to guide him in the design of the steamship, locomotive, and flying machine. Here he is forced to adopt some immediate line of action, leaving the abstract theorist to pursue his speculations at leisure. The engineer must deliver the goods to time.

The sui generis mass $\mathrm{M}=\mathrm{W} / \mathrm{g}$, Mach's terrestrial mass, implies unit mass of $g$, lb. ; Perry proposed for it the name "slug," about a $32 \mathrm{lb}$. shot. But slug in gunnery means any irregular piece of lead, cut off a church roof in civil war, and rammed down a fowling piece. It is curious to find sui generis mass in slugs still lurking in the engineers' table of moment of inertia of a body; it has even been found by force of habit in a cross-section area for moment of stiffness of a beam.

There is too much of the mere algebraical literal calculus in the presentation of dynamical theorems. Quantities receive a label, $\mathrm{M}, \mathrm{W}, g, v, s, t$, as in mere algebra, and this letter label is stuck on the quantity for identification, without sufficient explanation of the measurements required to translate the label into the description of an actual body, or its behaviour in motion and associated measurement.

But the writer of the usual text-book is obliged to keep in mind the needs of his class in preparing to meet the examiner, or is on the road to be an examiner himself in his turn, and his book adopted. . So the round goes on, and a curious jargon has arisen, cultivated by the schoolmaster and despised by the engineer.

Darboux surprised our company once by retailing the well-known story of the French Minister of Education, pulling out his watch and boasting how at that moment the same lesson was in progress in all the schools in France. I was so bold as to cut in-" Mais, il y a une suite." "Quelle suite?" "Le ministre a continué,--du même traité, de moi."

The Hospitalier notation is a ready escape from confusion when the derived unit appears, involving two or more of the three fundamental units. Then a velocity in feet or centimetres per second is indicated by $v, \mathrm{ft} . / \mathrm{sec}$. or $\mathrm{cm} . / \mathrm{sec}$., and an alteration of velocity per second by ft. $/ \mathrm{sec}^{2}$ or $\mathrm{cm} . / \mathrm{sec}^{2}$; thus $g=32 \cdot 2$, $\mathrm{ft} . / \mathrm{sec}^{2}$, or $9 \cdot 8 \mathrm{I}, \mathrm{m} . / \mathrm{sec}^{2}$ So, too, for density, in lb./ft. ${ }^{3}$, $\mathrm{gm} . / \mathrm{cm}^{3}{ }^{3} \mathrm{~kg} / \mathrm{m}^{\mathbf{3}}{ }^{,}$t. $/ \mathrm{m}^{3}{ }^{3}$ A moment of inertia, $\mathrm{Wk}^{2}$, would be in $\mathrm{lb} . / \mathrm{ft}^{2}$, and so on. But the adoption of this Hospitalier system is still very slow, although accepted by a resolution of the Paris Electrical Congress, I880, and again at Frankfurt, r89r.

Although absolute-measure of force is insisted on in all C.G.S. records, there is no accurate measurement of force except first in the gravitation unit of the gravity field, as with the Current Weigher-Balance; and after the experiment is complete, the factor $g$ is to be supplied, but often forgotten.

Rayleigh appears to be writing feelingly, quoted in Engineering, July 4, r9I9: "When a problem depends essentially on gravity, $g$ makes no appearance. But when gravity does not enter at all, $g$ obtrudes itself conspicuously, and requires to be kept carefully in its proper place" (as in electro-magnetic and elastic measurement).

All matter is transparent to gravity: there is no escape from it on the surface of the earth. In the work of the engineer to combat the powers of Nature, gravity is the force he is up against, and the strength of it provides him with the unit the engineer will never discard, as capable of immediate exact measurement. He will never abandon his gravitation units for such minute substitutes in the C.G.S. system, useful only for passing an examination, or for microscopic physical measurement.

Weighing and measuring must be carried out in a gravity field, and not in vacuo; the experimenter must be allowed to breathe in a warm room during a long careful measurement. The factor $g$ is inserted after the work is over, for calculation and record in absolute measure, and the C.G.S. system was invented to make calculations and tabulate them, not to weigh and measure, as Halsey pointed out.

The metric system is a legacy of the French Revolution, when all ancient tradition was swept away and the world to be started going afresh. Time and angle were to be decimalised with French logic. The quadrant was divided into roo grades, each of roo centesimal minutes; and a minute on the meridian was made into the kilometre-the unit of distance. But sexagesimal clocks, watches, and chronometers were not to be thrown into the sea for such a theoretical fad as centesimal time; and the ridiculous official names assigned to the days of a decimal week excited derision. Any attempt was bound to fail to bring music into line with the metric system, by a decimalisation of the octave.

Elsewhere the metric system has taken a firm hold in the civilised world, as a means of cosmopolitan commercial intercourse, and must be accepted. But the sailor will not surrender his cosmopolitan sexagesimal measure, of time and angle, inherited from the Chaldæan astronomer, and he continues to graduate the quadrant into ninety degrees, and the degree into sixty minutes, and he takes the sexagesimal minute of latitude on the meridian as his unit of length, and calls it a mile, geographical $(\mathrm{G})$, nautical $(\mathrm{N})$, sea $(\mathrm{S})$, or Italian, in the old books.

The sailor then starts a decimal subdivision of the mile, dividing it into ro cable, and the cable into roo

$$
\text { NO. } 2782 \text {, VOL. I I I] }
$$


fathom. Geodetical measurement makes this fathom a little more than $6 \mathrm{ft} .,-6 \cdot 08$, say $6 \mathrm{ft}$. and $\mathrm{I}$ inch over. Longitude he measures on his chronometer, giving sexagesimal time of 24 hours (h.) in the day, an hour of 60 minutes $(\mathrm{m}$.$) ; and a minute of 60$ seconds (s.) ; four seconds of longitude = one minute of longitude at the equator, or a mile, an easy range of eyesight. The schoolmaster cuts the fathom down to $6 \mathrm{ft}$. exactly, and would sweep it away as a useless load on the schoolboy's memory, although universal in sounding, as in

\section{"Full fathom five thy father lies."}

The schoolmaster has his eye, too, on the suppression of all the ancient measures of agriculture,-furlong, rod, pole, perch, rood, chain, ell, palm, hand. But the chain as the length of the pitch at cricket is too sacred to be assailed. And what is the height in C.G.S. centimetres of a horse $x$ hands high ? He is obliged to cling to the mile, the statute, land, military mile, of 8 furlongs, 80 chains, or I760 yards.

It is unfortunate the sailor carried the world mile on to his own unit, perhaps under a mistaken idea that the two miles were undistinguishable. Newton was arrested in his speculation on gravity by falling into this error. The land soldier mile is the one entitled to its name as the length of iooo paces (passus, not gradus), millia passum, M.P. on the Roman milestone, covered in marching along the road, making $5.28 \mathrm{ft}$. the double pace of the Roman soldier; this is cut down to $5 \mathrm{ft}$. in our modern drill book, and less still in the metric equivalent of the French soldier.

It is strange to read to-day in the "Admiralty Manual of Navigation," I9I4, page I, the earth is described as an oblate spheroid, greatest and least diameter 3963, $395^{\circ}$ miles (military, soldier, statute). In navigation the surface of the ocean is always treated as a perfect sphere, and of girth $360 \times 60=21600$ sea miles (S), making the radius of the sphere $343^{8} \mathrm{~S}$ miles, the length of the radian along a meridian. Besides the solecism of mentioning the military land mile as a measure in navigation, the real dimensions of the earth are double as stated in the Manual. Can we wonder then at an Admiral sending himself and his flagship to the bottom by a confusion between radius and diameter?

\section{The Royal Society.}

\section{Munificent Gift from Sir Alfred Yarrow.}

\section{THE} E generous gift from Sir Alfred Yarrow, announced in the subjoined letter from him to the president of the Royal Society, and gratefully accepted by the Society, is a most welcome acknowledgment from a great leader of industry of the practical service of scientific investigation. Sir Alfred, who was elected a fellow of the Society last year, has always taken an active interest in the progress of science and has promoted its application to industry in many waysdirectly in his own works and indirectly by gifts to educational and scientific institutions. His faith in science as the maker of the modern world is unbounded, and the words in which he gives expression to it should afford scientific workers both pride and encouragement. We are at the beginning of a new era of human history, and it is to the close association of science and industry, in the spirit of Sir Alfred Yarrow's letter, that we must look for strength to meet the difficulties before us. The Royal Society, and the scientific workers it represents, may be trusted to continue to extend the boundaries of natural knowledge, and if statesmen anc industrialists have the same progressive aims we can look with confidence to whatever the future may bring.

I would ask you to be so kind as to bring before the Council, at an early opportunity, the following proposals :

I have, for many years, held the view that the prosperity of this country has been greatly hampered in the past for the want of better promotion to scientific investigation and its application to practical affairs.

I am convinced that the future prosperity of this country will be largely dependent upon the encouragement of original scientific research. The birth of new industries, and the development of existing ones, are due largely to the growth of science, thus securing employment and the welfare of the whole community being advanced.

It is doubtful whether even yet it has been realised how completely this country would have been at the mercy of our antagonists in the late war, had it not been for the research work done by our scientific men before the war and during its course.

I desire to mark my sense of the value of research to the community by offering, as a gift to the Royal Society, Ioo,oool. to be used as capital or income for the purposes of the Society, as the Council may think fit, because I recognise conditions alter so materially from time to time that, in order to secure the greatest possible benefit from such a fund, it must be administered with unfettered discretion by the best people from time to time available.

Care must, of course, be taken that a gift from the fund shall in no case lessen any Government grant.

In accordance with your practice you would, I assume, appoint a Committee to administer the fund, and would also frame rules for the guidance of the Committee, while reserving the right to alter such rules from time to time; and I would suggest that they be reconsidered by the Council every tenth year so as to meet modern needs.

I should prefer that the money be used to aid scientific workers by adequate payment, and by the supply of apparatus or other facilities, rather than to erect costly buildings, because large sums of money are sometimes spent on buildings without adequate endowment, and the investigators are embarrassed by financial anxieties.

Although I thus give a general expression of my wishes, I do not intend, by so doing, to create any Trust or legal obligation for their fulfilment.

In conclusion, I should like to record my firm conviction that a patriotic citizen cannot give money, or leave it at his death, to better advantage than towards the development of science, upon which the industrial success of the country so largely depends.

A. F. YARROW.

NO. 2782 , VOL. 111 I] 